Отримано: 14 січня 2020 року

Прорецензовано: 23 січня 2020 року

Прийнято до друку: 29 січня 2020 року

e-mail: nastwol@ukr.net

DOI: $10.25264 / 2519-2558-2020-9(77)-51-55$
Lysetska N. H. Konzept «Europa» an der Schwelle zweier Jahrtausende. Наукові записки Наиіонального університету «Острозька академія»: серія "Філологія». Острог: Видво НаУОА, 2020. Вип. 9(77). С. 51-55.

УДК: 811.112.2-11

Nataliia H. Lysetska,

Doktor philologischer Wissenschaften, Dozent

Osteuropäische Lessja Ukrainka Nationaluniversität

\title{
KONZEPT „EUROPA“ AN DER SCHWELLE ZWEIER JAHRTAUSENDE
}

Der Artikel ist der Erforschung des Konzepts „Europa“ und seiner Werte in der deutschen Linguokultur Ende des 20. Anfang des 21. Jahrhunderts sowie der Analyse der Besonderheiten des Funktionierens der sprachlichen Einheiten innerhalb der zu untersuchenden kognitiven Struktur gewidmet. Es wurden folgende Aufgaben gelöst: 1) die Inhalte des Konzepts „Europa“ aufgrund der InternetQuellen zwecks der Aufdeckung der dominanten und systemimmanenten Relationen innerhalb des gleichnamigen Konzepts erforscht; 2) der evolutionäre Prozess der Formierung des Konzepts „Europa“ als Fragment des konzeptuellen Weltbildes gezeigt; 3) die in dem von H. Schmidt verfassten Buch „Die Deutschen und ihre Nachbarn. Menschen und Mächte II. “ Grundwerte des Konzepts „Europa“ erfasst und ergründet; 4) anhand der durchgeführten Analyse der deutschen Media-Texte (u. a. der teilweise verwendeten Topoi-Analyse der Argumentationsmuster) neu erworbene Bedeutungsschattierungen des Konzepts „Europa“ erschlossen und zusammengefasst.

Wie die Analyse des faktologischen Materials zeigt, ist das Konzept ,Europa“" „Gesamteuropa“ in der deutschen Linguokultur vieldeutig. Die dreidimensionale Struktur des Konzepts - begriffliche, bildliche und bewertende / aksiologische Komponenten - verändert sich im Laufe verschiedener historischer Zeitabschnitte und erhält neue inhaltliche Schattierungen. Die evolutionelle Dynamik in dem zur Untersuchung ausgewählten Zeitabschnitt sieht auf folgende Weise aus: eine geistige und multikulturelle Ganzheit (wo Christentum und europäische Sprachen dominierend sind) - ein einheitliches Europa, Gesamteuropa, Eurozone, das vereinte neue Europa - gespaltetes Europa, multikulturelles Europa (begriffliche Komponente); Europa ist ein Kaleidoskop (mit vielen miteinander friedlich lebenden Nationen) - Festung Europa (sowohl im positiven (Sicherheit für diejenigen, die vor der Gefahr des Krieges fliehen) als auch im negativen Sinne (Abgrenzung durch die Mauer) - Europa in Gefahr (bildliche Komponente); ein Ganzes mit demokratischer Staatsform und hohem Lebensstandard, in dem Menschenrechte verwirklicht werden (Westeuropa) - multikulturelles Europa-desorientiertes Europa (bewertende Komponente).

Die Untersuchung hat ergeben, dass der Inhalt des Konzepts „Europa“ nur durch die Zusammenwirkung verschiedener Faktoren (historischer, geographischer, ökonomischer, kultureller, religiöser, politischer, sozialer usw.) unter Berücksichtigung derer evolutionellen Dynamik in der Vergangenheit und auf der modernen Etappe der Entwicklung vollständig zu erschließen ist.

Schlüsselwörter: Dynamik, Evolution, das Konzept „,Europa“, konzeptuelle Merkmale, Topoi, Linguokultur, Diskurs, deutschsprachiger Diskurs.

Лисецька Наталія Григорівна,

кандидат філологічних наук, дочент

Східноєвропейський національний університет імені Лесі Украӥнки

\section{КОНЦЕПТ „ЕURОРА“НА ЗРІЗІ ДВОХ ТИСЯЧОЛІТЬ}

Стаття присвячена аналізу концепту „Еигора“ та його тлумаченню носіями німецької лінгвокультури на зламі двох тисячоліть. Досліджено смислове наповнення кониепту „Еигора“ на основі Інтернет-джерел для виявлення домінантних та системних відношень усередині однойменного кониепту; показано еволюиійний проиес формування кониепту „Еигора“ як фрагменту концептуальної картину світу; розглянуто поняття „Еигора“ ХХ століття на основі книги екс-канилера Німеччини Г. Шмідma „Die Deutschen und ihre Nachbarn. Menschen und Mächte II“; проаналізовано функиіонування концепту „Еигора“ в сучасному мас-медійному німеиькомовному просторі. Аналіз фактологічного матеріалу показав, шо кониепт „Еигора“ у німеиькомовніи лінгвокультурі є багатозначним. Трьохвимірна структура концепту - понятійна, образна і оцінна - змінюється й набуває нових змістових відтінків упродовж різних історичних проміжків часу. Еволюиійна динаміка обраного кониепту у межах окресленого часового простору виглядає так: EUROPA - духовна та багатонаціональна єдність (де християнство та європейські мови є визначальними), єдина Свропа, спільна Свропа / ein einheitliches Europa, Gesamteuropa, нова об'єднана Свропа / das vereinte пеие Europa, розколота Свропа / gespaltetes Europa (поняттєвий складник); Свропа - ие калейдоскоп / Europa ist ein Kaleidoskор, Eвропа - ие фортеия / Festung Europa, Свропа у небезпеці / Europa in Gefahr (образний складник); єдність із демократичною державною формою та високим рівнем життя з верховенством права (Західна Свропа) / ein Ganzes mit demokratischer Staatsform und hohem Lebensstandard, in dem Menschenrechte verwirklicht werden (Westeuropa), багатонаиіональна Свропа / multikulturelles Europa, дезорієнтована Свропа / desorientiertes Еигора (очінний складник). Доведено, щзо смисл концепту „Еигора“ можна повністю розкрити лише при врахуванні та поєднанні иілої низки чинників (історичних, географічних, економічних, культурних, релігійних, політичних, соціальних тощо) з урахуванням їх еволюиійної динаміки у минулому та на сучасному етапі розвитку.

Ключові слова: динаміка, еволюція, концепт „Еигора“, концептуальні ознаки, топос, лінгвокультура, дискурс, німецькомовний дискурс.

Nataliia H. Lysetska,

PhD (Doctor of Philosophy (in Philology)), Associate Professor

Lesya Ukrainka Eastern European National University

\section{THE CONCEPT „EUROPA“ ON THE THRESHOLD OF THE SECOND AND THIRD MILLENNIUM}

The article deals with the analysis of the concept „Europa“ and its interpretation by the speakers of German linguistic culture at the turn of the two millennia. The semantic content of the concept „Europa “ was explored on the basis of Internet sources for identifying dominant and systemic relationships within this concept; the evolutionary process of forming the concept „Europa " is shown as a fragment of the conceptual picture of the world; the concept „Europa“ of the XX century is discussed on the basis of the book by the ex-Chancellor of 
Germany G.Schmidt „,Die Deutschen und ihre Nachbarn. Menschen und Mächte II“; the functioning of the concept „Europa" in the modern German-language mass media is analyzed. The analysis of the factual material has revealed that the concept „Europa "in German-speaking linguistic culture has multiple meanings. The three-dimensional structure of the concept - notional, figurative and evaluative - changes and acquires new meaningful shades over different historical intervals. The evolutionary dynamics of the chosen concept within the defined temporal space are as follows: EUROPA - a spiritual and multinational unity (where Christianity and European languages are decisive), united Europe, common Europe / ein einheitliches Europa, Gesamteuropa, new united Europe / das vereinte neue Europa, split Europe / gespaltetes Europa (notional component); Europe is a kaleidoscope / Europa ist ein Kaleidoskop, Europe is a fortress / Festung Europa, Europe in danger / Europa in Gefahr (figurative component); unity with a democratic state form and a high standard of living with the rule of law (Western Europe) / ein Ganzes mit demokratischer Staatsform und hohem Lebensstandard, in dem Menschenrechte verwirklicht warden (Westeuropa), multinational Europe / multikulturelles Europa, disoriented Europe / desorientiertes Europa (evaluative component). It is proved that the meaning of the concept ,Europa " can be fully revealed only by taking into account and combining a number of factors (historical, geographical, economic, cultural, religious, political, social, etc)., taking into account their evolutionary dynamics in the past and at the present stage of development.

Key words: dynamics, evolution, concept „Europa“, conceptual features, topos, linguistic culture, discourse, German-language discourse.

Eines der wichtigsten Konzepte der Menschen, die sich mit den Europäern identifizieren, ist das Konzept „Europa“. Dieses Konzept ist nicht nur für die Deutschen, die in einem der stärksten Länder der EU leben, von Bedeutung, sondern auch für die Völker, die nach Europa streben, die EU Mitglieder werden möchten und die noch sehr viel dafür tun sollen. Das Interesse an dem untersuchten Problem sehen wir in den Artikeln mehrerer Wissenschaftler und Politiker. Das Konzept „Europa“ als Bestandteil des öffentlichen Diskurses ist Mittel und Beweis der nationalen Interpretation der Welt und Objekt der mentalen Geographie [3]. In der wissenschaftlichen Literatur wurde das Konzept „Europa“ unter verschiedenen Blickwinkeln untersucht, wie z. B. das vereinte Europa (M. Hnatjuk, Ja. Tschornohor, R. Barkowski), Europa als politische Idee (G. Münkler), die kognitiv-linguistischen Aspekte des Konzepts „Europa“ in der ukrainischen Publizistik (Ja. Prychoda) u.a.m.. Der Anfang des III. Jahrtausends war in vielen Bereichen des menschlichen Daseins unruhig. Zuerst kam die Finanzkrise, heute beobachten wir die humanitäre Katastrophe in vielen Ländern der Welt. Hunderttausende von Menschen aus den Ländern Afrikas und des Fernen Ostens verlassen ihr Zuhause, um ein besseres Leben zu finden. Der Krieg in Syrien, im Irak und in den anderen Ländern hat eine Massenflucht der Menschen nach Europa verursacht. Das Thema „Flüchtlinge“ ist ständig in den europäischen Medien, was auch das Interesse der Wissenschaftler zu linguistischen Untersuchungen brachte. In den letzten Jahren wurden Medien-Frames in den Nachrichten und in der Presse über Stereotype bezüglich der Ausländer (S. Schiffer 2005), Charakteristiken der ethnischen Minderheiten (H. Bonfadelli 2007), die Darstellung der Fremden als eine soziale Erscheinung in den Nachrichten des schweizerischen Fernsehens (M. Luginbühl 2007) und die der Jugend mit der Migrationsvergangenheit (T. Hermann, Ch. Hanetseder 2007, H. Moser 2007 u. a. m). untersucht, man hat auch typische argumentative Beispiele (Topoi) des Migrationstextkorpuses auf der Basis der Diskursanalyse (S. Jäger/ Jü.Link 1993; M. Wengeler 2006) und Charakteristiken des linguokulturellen Typs „Aussteiger“ (O. Bondarchuk) [4] erforscht. In diesem wissenschaftlichen Artikel führen wir auch kurz die Ergebnisse der Untersuchung der Migration in die EU-Länder in den Jahren 2015-2017 an, da sie das Konzept „Europa“ inhaltlich erweitern.

Die Aktualität des Artikels besteht in der Erforschung des Konzeptes „Europa“ und seiner Werte in der deutschen Linguokultur Ende des 20. Anfang des 21. Jahrhunderts sowie der Analyse der Besonderheiten des Funktionierens der sprachlichen Einheiten innerhalb der zu untersuchenden kognitiven Struktur.

Das Ziel des Artikels ist die Erforschung der Inhalte des Konzeptes „Europa“ durch die Wiedergabe des entsprechenden konzeptuellen Raums aufgrund der sprachlichen Einheiten zur Aktivierung des zu analysierenden Konzeptes im deutschsprachigen Diskurs.

Zur Realisierung des gestellten Ziels muss man folgende Aufgaben lösen: 1) die Formierung und die Bedeutung des Begriffs „Europa“ erforschen; 2) die in dem von H. Schmidt verfassten Buch „Die Deutschen und ihre Nachbarn. Menschen und Mächte II. “ Grundwerte des Konzeptes „Europa“ erfassen und ergründen; 3) das Funktionieren des Konzepts „Europa“ im modernen deutschsprachigen Medienraum analysieren; 4) anhand der durchgeführten Analyse der deutschen Media-Texte (u. a. der teilweise verwendeten Topoi-Analyse der Argumentationsmuster) neu erworbene Bedeutungsschattierungen des Konzepts „Europa“ erschließen und zusammenfassen.

Bei der Analyse der Konzepte schließen wir uns der Wolgograder wissenschaftlichen Schule von W. I. Karasik an und erforschen die dreidimensionale Struktur des Konzepts: begriffliche, bildliche und wertende/aksiologische Komponenten. Den Begriff Europa betrachten wir als Konzept [1], weil er diese drei Komponenten enthält (aufweist).

Die Gedanken zum Europa-Begriff und die eigene Sicht von Europa im XX. Jahrhundert sind im Buch des bekannten ExKanzlers Deutschlands Helmut Schmidt dargelegt „Die Deutschen und ihre Nachbarn. Menschen und Mächte II. “ [5, S. 444447]. Nach der Meinung von H. Schmidt, war der Europa-Begriff oft genug eng und unklar verstanden. Wenn das Land zur WEU (Westeuropäische Union), zur EGKS (Europäische Gemeinschaft für Kohle und Stahl), zum Europa-Rat oder zur EWG (Europäische Wirtschaftsgemeinschaft) gehörte, so wurden die Bürger dieses Landes als Europäer identifiziert. Wer dagegen war, der wurde AntiEuropäer genannt. Selbstverständlich ist der Inhalt des Europa-Begriffs nicht leicht zu erfassen. Geographisch gesehen war Europa als das Territorium zwischen Island und Bosporus, Gibraltar und Ural verstanden. Auf dieser Mappe gehört die Türkei zu Asien, und die Ehrenstadt Visantij, die heutige Stambul, - zu Europa. Strittig bleibt die Frage wegen Russen, die im Ostteil des Ural leben, die Wurzeln im fernen Sibirien haben, die Mehrheit der Bevölkerung bilden und denen die Zugehörigkeit zu Europa versprochen war. Wie wir sehen, gibt die Geographie keine klare und eindeutige Antwort auf eine Europa-Identität [5, S.444].

Europa ist eine kulturell-politische Idee, die im Laufe der geschichtlichen Entwicklung überdacht wird und einen neuen Inhalt bekommt. Nach der Überzeugung von H. Schmidt, hat das Christentum Europa vereinigt und es zu einer geistigen Einheit gemacht: „Das Christentum hat Europa zu einer geistigen Einheit gemacht. Man könnte es die europäische Religion nennen. “ [5, S. 445]. Das ist eine europäische Religion, die sich später außerhalb der geographischen Rahmen von Europa verbreitet hat und zu einer Weltreligion wurde.

Das Konzept Europa ist eng mit der Kultur verbunden. Zum kulturellen Erbe von Europa gehören auch europäische Sprachen, die in der ganzen Welt gesprochen werden und europäische Werte auf vielen „nicht europäischen Kontinenten“ verbreiten. Diesbezüglich 
ein Zitat: „, Mit der Anerkennung des Multikulturalismus verlässt Europa einen Sonderweg der Geschichte, der unendliches Leid über den Kontinent gebracht hat; kehrt einer Vorstellung den Rücken, die immer schon verlogen war. Der Idee nämlich, die verschiedenen Nationen müssten aus ethnisch und kulturell homogenen "Staatsvölkern» bestehen“. (Die Welt, 27.02.15). Das Konzept „Europa“ basiert auf Vielfalt und Varietät.

Bei der Analyse des Konzepts „Europa“ muss man den soziokulturellen Faktor berücksichtigen, er kann aber nicht wechselseitig den Sinn des Konzepts wiedergeben. H. Schmidt versucht auch eine politische Definition des Konzepts Europa zu geben. Er lenkt unsere Aufmerksamkeit darauf, dass das zaristische Russland bis zu seinem Ende als ein europäischer Staat galt. Später, nach der bolschewistischen Revolution, war der Versuch aus politischen Gründen die Westgrenze von der Sowjetunion als Ostgrenze von Europa zu definieren. Die Versuche, die Grenze zwischen Demokratie und Kommunismus zu ziehen, waren auch vergebens, weil die Teilung im Laufe von 40 Jahren durch das Herz von Deutschland - Berlin - verlief und eine Nation künstlich trennte [5].

Die Frage, wo Europa beginnt und endet, ist sekundär, obwohl man auch diese Frage nicht aus der Sicht lassen kann. Wenn die Grenzen der Europäischen Gemeinschaft aus der politischen Sicht sich bis nach Kleinasien, dem Nahen Osten und Nordamerika ausbreiten würden, so würden Probleme entstehen, die man nicht lösen könnte, und zwar aus dem religiösen, sozialen und kulturellen Grund. Andererseits wäre die Verbreitung der Europäischen Gemeinschaft nur nach dem ethnischen Prinzip falsch [5]. Das Kriterium der Vitalität ist außerordentlich wichtig für die Europa-Identität.

Europa, nach der Meinung des Politikers, - das ist nicht etwas viel Größeres und Breiteres, als das Territorium von Nato oder Eurounion, das ist eine Einheit, die aus dem Rahmen der geschichtlich bedingten politischen Vereinigungen fällt: „Europa ist nicht nur viel größer und weit mehr als der Bereich der NATO oder der EU, es ist als Ganzes auch wichtiger als irgendwelche historisch bedingten politischen Zusammenschlüsse. Die Attraktivität des Westens, in dem die Menschenrechte und die demokratische Staatsform weitgehend verwirklicht sind, dessen Volkswirtschaften viel besser funktionieren und dessen durchschnittlicher Lebensstandard weit höher liegt, als im Osten, diese Attraktivität wird - das war für mich eine Gewissheit - eines Tages dazu führen, dass beide Teile Europas sich wieder füreinander öffnen. “ [5, S. 446]. Schlüsselwörter des Konzepts „Europa“ sind Menschenrechte, demokratische Staatsform und hoher Lebensstandard.

Europa ähnelt dem Kaleidoskop, so H. Schmidt. Wir bilden eine konzeptuelle Metapher daraus, die zur bildlichen Komponente des Konzepts „Europa“ gehört: Europa ist ein Kaleidoskop. Das Zusammenleben und die Entwicklung von vielen verschiedenen Nationen ist die ausschlaggebende Eigenschaft von Europa und seiner Geschichte. Dieser Aspekt bildet die aksiologische (wertende) Komponente des analysierten Konzepts: mit positiven und negativen Erscheinungen und Ereignissen, wobei die Menschlichkeit die Spitze übernimmt und hilft, das Negative zu beseitigen.

Demzufolge ist EUROPA Ende der 90-er Jahre nach Auffassung von H. Schmidt [5] eine geistige Einheit mit Christentum als europäischer Religion und eine multikulturelle Ganzheit mit europäischen Sprachen, die europäische Werte auf vielen ,nicht europäischen Kontinenten“" verbreiten (begriffliche Komponente). Das ist ein Ganzes mit demokratischer Staatsform und hohem Lebensstandard, in dem Menschenrechte verwirklicht werden (Westeuropa) (bewertende Komponente). Europa ist ein Kaleidoskop mit vielen miteinander friedlich lebenden Nationen (bildliche Komponente).

Jetzt versuchen wir das Bild von Europa des 21. Jahrhunderts aufgrund der Artikel des deutschen politischen Diskurses aufzudecken. Bei der Analyse des Korpus DWDS [6] und der Zeitungen „Die Zeit“ u.a.m. (2000-2014), (Westfalen-Blatt, 2015) u.a.m. haben wir festgestellt, dass Lexem Gesamteuropa mit der Lexik mit folgenden konzeptuellen Merkmalen präsentiert ist: ein einheitliches Europa (Gesamteuropa als solches (eine Einheit), die Konjunktur für Gesamteuropa), das ökonomische Wachstum des Gesamteuropa (das Wachstum in Gesamteuropa, das Wachstum für Gesamteuropa, auch in Gesamteuropa gelang eine Steigerung, der industrielle Kern Gesamteuropas, die wirtschaftliche Entwicklung Gesamteuropas), die Stabilität des Gesamteuropa (die Stabilität Gesamteuropas), Eurozone und Gesamteuropa (in der Eurozone wie auch in Gesamteuropa), Deutschland - ein starkes ökonomisches Land in der EU (in Westeuropa außerhalb Deutschlands sank der Absatz jedoch leicht, Gesamteuropa möge möglicherweise nahe am Rande einer Rezession stehen, Deutschland nicht, nicht ganz so stark wuchs das Geschäft in Gesamteuropa). Auffallend ist die Gegenüberstellung von Europa zu Gesamteuropa, hier wird gemeint, dass die EU-Länder Europa sind, und alle anderen Länder zusammen mit der EU sind Gesamteuropa: „Das deutsche Maßnahmenpaket könne sich in Europa nicht nur sehen lassen, sondern helfe auch Gesamteuropa, die Krise zu überwinden. " (Die Zeit, 13.01.2009).

Anfang des III. Jahrtausends gibt Europa viele Hoffnungen. In der unten angeführten Textpassage wird das konzeptuelle Merkmal von Gesamteuropa als neues Europa aktiviert: „Am Anfang des 21. Jahrhunderts nun steht Europa wieder vor einem großen Schritt - hin zu einem vereinten Gesamteuropa unter Einschluss der Türkei und vieler Staaten des ehemaligen Ostblocks. Auch dieses neue Europa kann nicht von oben beschlossen werden, von Diplomaten und Staatsmännern, Bankiers und Bürokraten und sonst welchen «Eliten». “(Die Zeit, 13.01.2000).

Konzeptuelle Merkmale der Vielfalt, Attraktivität, Unübertroffenheit und Nichtordinalität sind für das Europa des XXI. Jahrhunderts typisch: „Nur, hat es in der Geschichte schon einmal einen demokratischen Staat gegeben, der 500 Millionen Einwohner umfasste und mehrere Dutzend Sprachen? In Wahrheit wissen wir nicht, welches die ideale Staatsform ist, weil es für das demokratische Gesamteuropa keinen Präzedenzfall gibt, weder das Römische Reich noch das Heilige Römische Reich deutscher Nation, noch Napoleons Empire, noch die USA. Vielleicht ist ja im Moment das für Europa richtig und angemessen, was wir gerade haben (plus Lissabon-Vertrag). “ (Die Zeit, 04.06.2009).

Eine der neuesten und aktuellsten Bedeutungen des Begriffs „Europa“ im 21. Jahrhundert ist Europa-Festung, die Asyl Millionen von Flüchtlingen aus der arabischen Welt (Syrien, Irak, Ägypten) und anderen Kontinenten gibt, die gezwungen sind, Schutz vor Krieg, Kälte, Terror, Hunger, Unrecht und Ruinieren zu suchen. Das Lexem Europa-Festung (Festung Europa) wird auch in negativer Bedeutung der bewertenden Komponente des Konzepts gebraucht, indem strengere Trennung und Grenzen gemeint werden. Die österreichische Politikerin (von 2011 bis 2016 österreichische Innenministerin) J. Mikl-Leitner forderte eine Festung Europa zu bauen: „Die derzeitige Situation in Slovenien, Österreich oder auch in Deutschland beweist, dass wir so rasch wie möglich an einer Festung Europa bauen müssen. (BZ 30.10.15). „Seit Mitte September gibt es Grenzkontrollen zwischen Bayern und Österreich, wo zu Tausende Flüchtlinge in die Republik kommen. Österreich spricht von einer „Festung Europa. “(Westfalen-Blatt, 30.10.15). 
Infolge der Analyse der Zeitungsartikel für die Jahre 2000-2014, 2015 wurden folgende weitere inhaltliche Nuancierungen des Konzepts „Europa“ festgestellt: einheitliches Europa, Gesamteuropa, Eurozone, das vereinte neue Europa (begriffliche Komponente); Festung Europa (sowohl im positiven (Sicherheit für diejenigen, die vor der Gefahr des Krieges fliehen) als auch negativen Sinne (Abgrenzung durch die Mauer) (bildliche Komponente); Vielfalt, Attraktivität, Unübertroffenheit und Nichtordinalität (bewertende Komponente).

Der heutige Begriff „Europa“ evoziert vor allem noch solche aktuellen Inhalte: Flüchtlinge und Krieg gegen Terror, die in die Kategorie der selbständigen Konzepte übergehen, weil sie zu einem globalen Problem und einer grauenhaften Realität in der ganzen Welt geworden sind und somit auch Europa stark berühren und neue Bedeutungsschattierungen des Konzepts „Europa“ bilden.

In diesem Zusammenhang möchten wir das Konzept „Flüchtlinge“ nur flüchtig (kurz) erwähnen, das in unserer Untersuchung aus dem Jahr 2018 „Топос-аналіз концепту „Flüchtlinge“ в сучасному німецькомовному дискурсі“ detailliert analysiert wurde [2]. In dieser Abhandlung werden nur die wichtigsten Ergebnisse der Analyse der „Topoi“ bzw. der Argumentationsmuster aufgeführt. Die aus dem Textkorpus implizit abgeleiteten Argumentationsmuster zeigen die Migration als ein gesellschaftliches Problem und sie erweitern wesentlich das Konzept „Europa“, indem sie die Vorurteile der europäischen Gemeinschaft den Flüchtlingen gegenüber aufdecken und somit die europäischen Werte bzw. die Situation in ganz Europa zum Ausdruck bringen:

1. Europa in Gefahr (Der Europa-Alptraum-Topos). Die große Anzahl von Flüchtlingen im August - September 2015 ist zu einer großen Aufforderung für Europa geworden. Der damalige Finanzminister W. Schäuble vergleicht den Flüchtlingsstrom nach Europa mit einer Lawine, die innerhalb der Eurounion Europarisse und existenzielle Krise verursacht hat, was ihre Existenz bedrohen könnte: „Ob wir schon in dem Stadium sind, wo die Lawine im Tal unten angekommen ist, oder ob wir in dem Stadium im oberen Drittel des Hanges sind, weiß ich nicht.... Wenn wir im oberen Drittel des Hanges sind, ist das Bild von der Lawine eine ziemliche Herausforderung. "(BZ, 13.11.2015).

2. Desorientiertes Europa (Europa im Chaos und Durcheinander - Der Chaos-Topos).: , ,... tote Flüchtlinge im Mittelmeer, Chaos auf der Balkanroute, Hickhack zwischen den osteuropäischen Ländern, ... es gibt hierzulande Brände, wo Flüchtlinge unterkommen sollten.... Es ist eine wahre Schande! ... Die neue Völkerwanderung lässt sich nicht aufhalten. “(WB, 17.09.15).

3. Ein starkes und friedliches Europa (Der Wertegemeinschaft-Europa-Topos): Der Expräsident Deutschlands Joachim Gauck spricht von einer europäischen Wertegesellschaft mit friedlicher Zusammenarbeit und ihren Stärken: „Europa muss den Beweis antreten, dass es die Wertegemeinschaft ist,... Zudem gehe es um ,ein Europa der friedlichen Zusammenarbeit der Religionen und Kulturen. “... Wir stehen für ein Europa ein, das sich gerade im Angesicht von Krisen und Herausforderungen seiner großen Stärken versichern kann und im Sinne seiner großen Errungenschaften handeln muss. "(WB, 22.09.15).

4. Gespaltetes Europa (Der Proteste-Topos. Europa spaltet sich): Man beobachtet oft rechtsradikale und extremistische Stimmung innerhalb der Europäischen Union und in ganz Europa: „Die Krise... spielt den Rechtspopulisten und Rechtsextremen überall in Europa in die Karten. “ (FA, 24.10.15). ,.. Rechte Krawallmacher belagerten am Freitagabend die Zufahrt, skandierten ausländerfeindliche Parolen und warfen eine Flasche gegen einen Bus mit Asylbewerbern ... Zwei 18 und 34 Jahre alte Männer zeigten den Hitlergruß. " (Der Kurier, 19.09.15). Außerdem gibt es keine Einigkeit innerhalb der EU - die einen Mitgliedsstaaten der EU weigern sich, Flüchtlinge in ihren Ländern aufzunehmen: „....man kann sich nicht nur die Rosinen im Kuchen herauspicken, wenn sie Mitglied der EU sind, der viele Länder aus auch gerade in Mittel- und Osteuropa beigetreten sind, weil es eine Wertegemeinschaft... mit Demokratie, Menschenrechten und Rechtsstaatlichkeit ist. Da muss man ihnen sagen: Wenn ihr das wollt und wenn ihr in den Binnenmarkt wollt und die Personenfreizügigkeit, dann müsst ihr euch auch jetzt an diesem Punkt solidarisch zeigen und Flüchtlinge aufnehmen ... Europa der zwei Geschwindigkeiten ... die Länder, die in der Integration weitermachen wollen und andere hinten zurückbleiben... Europa ist und bleibt eine Wertegemeinschaft auch wenn über Flüchtlingsfrage gestritten wird... " (Deutschlandfunk, 30.01.16).

5. Zukunftsorientiertes Europa (Der Topos eines neuen Wirtschaftswunders): Die Politiker versuchen bei der Bevölkerung positive Einstellung den Flüchtlingen gegenüber zu wecken. Es ist vorteilhaft für Europa, weil viele Flüchtlinge Europa wirtschaftlich und intellektuell stärken können: „,Einige hoffen auf ein neues Wirtschaftswunder... “ (Die Welt, 19.09.15); ,... aus den Migranten ... können motivierte, intelligente, gebildete und einsatzbereite Arbeitskräfte werden, welche die alternden deutschen Arbeitnehmer ersetzen... “(Die Welt, 20.09.15); „,Flüchtlinge können Deutschland stärken... “(WB, 24.09.15).

Wie die Topos-Analyse zeigt, kommen nach 2015 neue inhaltliche Schattierungen im Konzept „Europa“ hinzu und nämlich gespaltetes Europa (begriffliche Komponente), Europa in Gefahr (bildliche Komponente) und desorientiertes Europa (bewertende Komponente).

Wie die Analyse des faktologischen Materials zeigt, ist das Konzept „Europa“ / „Gesamteuropa“ in der deutschen Linguokultur vieldeutig. Die dreidimensionale Struktur des Konzepts - begriffliche, bildliche und wertende/aksiologische Komponenten verändert sich im Laufe verschiedener historischer Zeitabschnitte und erhält neue inhaltliche Schattierungen, was die Ergebnisse der durchgeführten Forschung belegen. In dem zur Untersuchung ausgewählten Zeitabschnitt beobachtet man die evolutionelle Dynamik des Konzeptes „Europa“ auf folgende Weise: eine geistige Einheit mit Christentum als europäischer Religion und eine multikulturelle Ganzheit mit europäischen Sprachen - ein einheitliches Europa, Gesamteuropa, Eurozone, das vereinte neue Europa - gespaltetes Europa, multikulturelles Europa (begriffliche Komponente); Europa ist ein Kaleidoskop (mit vielen miteinander friedlich lebenden Nationen) - Festung Europa (sowohl im positiven (Sicherheit für diejenigen, die vor der Gefahr des Krieges fliehen) als auch im negativen Sinne (Abgrenzung durch die Mauer) - Europa in Gefahr (bildliche Komponente); ein Ganzes mit demokratischer Staatsform und hohem Lebensstandard, in dem Menschenrechte verwirklicht werden (Westeuropa) - Vielfalt, Attraktivität, Unübertroffenheit und Nichtordinalität - desorientiertes Europa (bewertende Komponente).

Nur die Zusammenwirkung verschiedener Faktoren (historischer, geographischer, ökonomischer, kultureller, religiöser, politischer, sozialer usw). unter Berücksichtigung derer evolutionellen Dynamik in der Vergangenheit und auf der modernen Etappe der Entwicklung ermöglicht den Inhalt des Konzepts „Europa“ zu erschließen.

\section{Література:}

1. Лисецька Н. Г. Концепт «Еuropa» у німецькій лінгвокультурі. Наукові записки Ніжинського державного університету імені Миколи Гоголя. Сер. : «Філологічні науки». Книга 1. Ніжин : НДУ ім. М. Гоголя, 2016. С. 175-180. 
2. Лисецька Н. Топос-аналіз концепту «Flüchtlinge» в сучасному німецькомовному дискурсі. Актуальні питання іноземної філології : наук. журн. / (редкол. : І. П. Біскуб (гол. ред). та ін.). Луцьк : Східноєвроп. нац. ун-т ім. Лесі Українки, 2018. № 8. С. 191-197.

3. Прихода Я. Концепт Свропа в українській публіцистиці: когнітивно-лінгвістичні аспекти : автореф. дис. на здобуття наук. ступеня канд. філол. наук : спец. 10.01.08 - «журналістика». Львів, 2005. 16 с.

4. Bondarchuk O. Frame-Analyse des Konzepts „Aussteiger“. Science and Education. A new dimension. Philologie. Issue. Budapest, 2015. № 3 (10). P. 9-12.

5. Schmidt H. Die Deutschen und ihre Nachbarn. Menschen und Mächte II. Berlin : Siedler Verlag, 1990. 571 S

6. Ziem A. Frames und sprachliches Wissen. Kognitive Aspekte der semantischen Kompetenz. Berlin, New York : Walter de Gruyter, 2008. $485 \mathrm{~S}$.

7. www.dwds.de. 